\title{
Sensitivity of the U.S. Blumeria graminis f. sp. tritici Population to Demethylation Inhibitor Fungicides
}

\author{
Emily Meyers, ${ }^{1}$ Consuelo Arellano, ${ }^{2}$ and Christina Cowger ${ }^{1,3,+}$ \\ ${ }^{1}$ Department of Entomology and Plant Pathology, North Carolina State University, Raleigh, NC 27695 \\ ${ }^{2}$ Department of Statistics, North Carolina State University, Raleigh, NC 27695 \\ ${ }^{3}$ United States Department of Agriculture, Agricultural Research Service, Raleigh, NC 27695
}

Abstract

\begin{abstract}
Wheat powdery mildew, caused by Blumeria graminis f. sp. tritici, is managed in the United States with cultivar resistance and foliar fungicides. Despite high levels of fungicide sensitivity in other cereal mildew populations, fungicide sensitivity of U.S. B. graminis f. sp. tritici has never been evaluated. Almost 400 B. graminis f. sp. tritici isolates were collected from 15 U.S. states over 2 years and phenotyped for sensitivity to two widely used demethylation inhibitor (DMI) fungicides, tebuconazole and prothioconazole. A large range of sensitivity to both DMIs was observed, with more insensitive isolates originating from the eastern United States (Great Lakes, Mid-Atlantic, and Southeast regions) and more sensitive isolates from central states (Plains region, Arkansas, and Missouri). Crossresistance was indicated by a positive although weak association between tebuconazole and prothioconazole sensitivities at all levels of analysis $\left(\mathrm{EC}_{50}\right.$ values, $\left.P<0.0001\right)$. A possible fitness cost was also associated with
\end{abstract}

prothioconazole insensitivity $(P=0.0307)$ when analyzed at the state population level. This is the first assessment of fungicide sensitivity in the U.S. $B$. graminis f. sp. tritici population, and it produced evidence of regional selection for reduced DMI efficacy. The observation of reduced sensitivity to DMI fungicides in the eastern United States underlines the importance of rotating between chemistry classes to maintain the effectiveness of DMIs in U.S. wheat production. Although cross-resistance was demonstrated, variability in the relationship of $\mathrm{EC}_{50}$ values for tebuconazole and prothioconazole also suggests that multiple mechanisms influence $B$. graminis $\mathrm{f}$. sp. tritici isolate responses to these two DMI fungicides.

Keywords: Blumeria graminis f. sp. tritici, demethylation inhibitor, DMI, $\mathrm{EC}_{50}$, fungicide sensitivity, prothioconazole, tebuconazole, wheat powdery mildew
Cereal powdery mildew is caused by host-specific formae speciales of Blumeria graminis (DC.) Speer, an obligately biotrophic ascomycete fungal plant pathogen with global incidence. The two most prominent formae speciales are $B$. graminis f. sp. tritici, which specializes on wheat (Triticum aestivum), and B. graminis f. sp. hordei, the barley (Hordeum vulgare) form. Epidemics are favored by cool, humid conditions and are characterized by polycyclic development in which spore loads can build up to extremely high levels (Both and Spanu 2004). The pathogen population is characterized by great genetic diversity and regular sexual recombination (Wicker et al. 2013), giving it a high evolutionary potential (Cowger et al. 2018; McDonald and Linde 2002). Powdery mildew can reduce grain yield by up to $30 \%$ if left unmanaged, because early-season infection leads to decreased production of additional stems and spikes (tillering) of cultivated cereal crops (Bowen et al. 1991).

Management of cereal powdery mildew has relied on cultivar resistance, both quantitative and qualitative, and fungicide applications. Worldwide, approximately 85 major barley powdery mildew $(M l)$ and 80 major wheat powdery mildew $(\mathrm{Pm})$ resistance gene variants have been identified in barley, wheat, or other closely related wild

${ }^{\dagger}$ Corresponding author: C. Cowger; christina.cowger@ars.usda.gov

Mention of trade names or commercial products in this article is solely for the purpose of providing specific information and does not imply recommendation or endorsement by the United States Department of Agriculture (USDA). USDA is an equal opportunity provider and employer.

*The $\boldsymbol{e}$-Xtra logo stands for "electronic extra" and indicates that four supplementary figures are published online.

The author(s) declare no conflict of interest.

Accepted for publication 24 July 2019.

This article is in the public domain and not copyrightable. It may be freely reprinted with customary crediting of the source. The American Phytopathological Society, 2019. grasses (Jørgensen and Wolfe 1994; McIntosh et al. 2013; Wiersma et al. 2017). When $M l$ or $P m$ genes with strong effects are deployed, $B$. graminis can rapidly defeat them due to its high adaptive capacity (Cowger et al. 2018; Parks et al. 2008). Frequent monitoring and surveys of European cereal powdery mildew populations revealed a breakdown of several $M l$ genes in the 1980s (Brown et al. 1990, 1991, 1993).

Demethylation inhibitor (DMI) fungicides are commonly used to reduce cereal powdery mildew severity. This group of chemicals hinders B. graminis growth by interfering with production of ergosterol, a key component of fungal cell membranes (Siegel 1981). Just as with resistance genes, fungicide efficacy can erode rapidly due to the high adaptive capacity of Blumeria. The Fungicide Resistance Action Committee (FRAC) ranks DMI fungicides (FRAC group 3) at moderate risk for the development of fungicide resistance (Brent and Hollomon 2007). In combination with the pathogen's evolutionary potential, this creates a high likelihood that insensitivity will develop in $B$. graminis populations in geographic areas where DMI fungicides are repeatedly applied.

Not long after DMI fungicides were introduced, European cereal mildew populations became DMI resistant. Several first-generation DMIs (such as triadimefon, triadimenol, and propiconazole) were approved for agricultural use in Europe in the late 1970s and early 1980s and were applied intensively to cereal crops to control widespread powdery mildew epidemics (Hoffmann 1986; Wolfe and Limpert 1987). Over the next decade, decreased DMI sensitivity was documented in B. graminis f. sp. tritici populations in the Netherlands (de Waard et al. 1986), the United Kingdom (Fletcher et al. 1987), the Czech Republic (Švec et al. 1995), and France (Godet and Limpert 1998). In cases in which multiple first-generation DMIs were evaluated, cross-resistance was noted in Czech isolates and British isolates (Švec et al. 1995; Wyand and Brown 2005). The same reduction in DMI sensitivity and cross-resistance were observed in European $B$. graminis f. sp. hordei populations, and DMI resistance was also found in progeny of resistant $\times$ sensitive isolate crosses (Blatter et al. 1998; Wyand and Brown 2005). In addition, Australia has seen a substantial decrease in the efficacy of some DMIs on barley powdery mildew (Tucker et al. 2015). 
Highly intensive use of DMIs on European wheat and barley has led to the demise of these fungicides as a useful tool for powdery mildew control and created a need for the development and release of other fungicide chemistries. However, B. graminis f. sp. tritici quickly became well known for overcoming fungicides, evolving resistance to six different chemical classes in only 2 to 5 years after their initial release (FRAC 2013). In fact, FRAC has now ranked $B$. graminis in the highest risk category for development of fungicide resistance (FRAC 2013).

In the United States (U.S.), wheat powdery mildew occurs nearly annually in the cool, humid Mid-Atlantic states (Maryland, Virginia, North Carolina, and South Carolina). The disease can also be found fairly frequently across the winter wheat area east of the Mississippi River and sporadically on hard winter wheat in the Central Great Plains (Cowger et al. 2012). However, recent U.S. B. graminis f. sp. tritici epidemics have occurred as far northwest as Montana (M. Burrows, 2015 and 2016, personal communication) and as far southeast as Georgia and Alabama (J. Johnson, 2014, and K. Bowen, 2013 and 2014, personal communication). Geographic expansion of this disease suggests a need for more effective wheat powdery mildew management in the U.S. through deployment of Pm genes in cultivars with quantitatively mildew-resistant backgrounds and regular monitoring of both Pm-gene efficacy and fungicide resistance development.

Understanding both the virulence profile of a regional $B$. graminis population and its fungicide sensitivity level is important to achieve durable and reliable cereal powdery mildew management. In the U.S., wheat $P m$-gene efficacy has lately been assessed once every 10 years, and rapid breakdown of a $P m$-gene has been observed several times (e.g., Pm4a in 2002 and Pml7 in 2009) (Cowger et al. 2009, 2018; Niewoehner and Leath 1998; Parks et al. 2008). However, the fungicide sensitivity of the U.S. B. graminis f. sp. tritici population has never been evaluated. Despite decades of fungicide use on wheat in the U.S., neither data on U.S. B. graminis f. sp. tritici baseline fungicide sensitivity nor periodic surveys have been published.

An increase in fungicide use on U.S. wheat has occurred over the last decade (Fernandez-Cornejo et al. 2014). U.S. wheat growers found an economic benefit in applying fungicides following a surge in the U.S. wheat market price in 2007 (Lopez et al. 2015; Thompson et al. 2014). Most eastern U.S. wheat growers continue to make at least one fungicide application per growing season, even though prices have returned to less favorable levels (C. Cowger, personal observation). Even with annual DMI applications on wheat in most regions of the country, DMI fungicide sensitivity of B. graminis $\mathrm{f}$. sp. tritici has never been evaluated in the U.S.

With the goal of helping avert the high degree of DMI resistance present in European cereal mildew populations, we set out to determine current levels of U.S. B. graminis f. sp. tritici sensitivity to several fungicide chemistries. Here, we report on the sensitivity of U.S. B. graminis f. sp. tritici to two commonly applied DMI fungicides: (i) tebuconazole, a "first-generation" DMI registered in the U.S. in 1994 and approved for use on wheat in 1997 (FAO 1998) and (ii) prothioconazole, a "second-generation" DMI registered in 2007 (FAO 2009). This study is the first evaluation of U.S. B. graminis f. sp. tritici sensitivity to any fungicide. To our knowledge, this is also the first evaluation of $B$. graminis f. sp. tritici sensitivity to prothioconazole internationally and the second evaluation of tebuconazole, with the only other study being in 1993 in Central Europe (Godet and Limpert 1998).

We hypothesized that both DMI fungicides would be less effective at controlling B. graminis f. sp. tritici isolates from the MidAtlantic U.S. states, where wheat powdery mildew epidemics and fungicide applications occur each year. Additionally, we expected isolates from the Great Plains states, where wheat powdery mildew occurs only sporadically, to be successfully controlled by both DMI fungicides. Across the U.S., we also anticipated $B$. graminis f. sp. tritici populations to be relatively less sensitive to the older DMI, tebuconazole, than to the newer DMI, prothioconazole.

\section{Materials and Methods}

B. graminis f. sp. tritici isolate collection. $B$. graminis f. sp. tritici-infected wheat plants were collected in the U.S. in 2013 and 2014 as described in Cowger et al. (2018). Approximately 390 of the over 1,000 genetically pure isolates in that collection were used in this study. These isolates were collected from 27 fields in 15 states and grouped into five geographic regions (Fig. 1, Table 1) based on previous population subdivision analysis (Cowger et al. 2016). Although they are geographic neighbors, the Plains and Arkansas/Missouri (AR-MO) B. graminis f. sp. tritici populations proved to possess different virulence profiles, likely because the two regions cultivate hard and soft wheat, respectively (Cowger et al. 2018). Isolates were maintained on B. graminis f. sp. tritici-susceptible detached leaves of universally susceptible cultivars 'Chancellor' or 'Jagalene' and incubated at $17^{\circ} \mathrm{C}$ with $12 \mathrm{~h}$ of light.

Historic European standard isolates JIW11 and Fel09 were kindly provided by B. Keller and maintained in live culture along with the U.S. isolates. DMI-sensitive isolate JIW11 was collected in the United Kingdom in 1985. DMI-resistant isolate Fel09 was collected in Germany in 1998. These isolates were also subjected to the same fungicide sensitivity assays as U.S. isolates and compared with U.S. isolates as controls. Both European isolates had been included in a prior study evaluating DMI (triadimenol and propiconazole) sensitivity (Wyand and Brown 2005).

Detached-leaf fungicide sensitivity assay. Formulated tebuconazole and prothioconazole were obtained from Bayer CropScience (Research Triangle Park, NC) in the form of Folicur and Proline, respectively. Stock solutions of $500 \mathrm{mg} /$ liter of active ingredient were prepared in water and used to make 11 concentration dilutions per fungicide. These tebuconazole $(0.219,0.438,0.875,1.75,3.5,7$, 10, 14, 17, 20, and $24 \mathrm{mg} / \mathrm{liter})$ and prothioconazole $(5,10,20,40$, $80,110,160,200,250,300$, and $350 \mathrm{mg} / \mathrm{liter}$ ) concentrations were determined in a preliminary pilot study using seven U.S. B. graminis f. sp. tritici isolates collected in 2013. In each case, the range was designed to capture the spectrum of $B$. graminis f. sp. tritici sensitivity by including high concentrations that prevented growth of all tested isolates, while still maintaining precision in predicting isolate sensitivity.

Ten-day-old universally susceptible ('Chancellor' or 'Jagalene') wheat seedlings were sprayed with a fungicide concentration to runoff using an atomizer. A sprayed water control was also included. Plants were allowed to dry $20 \mathrm{~min}$ in the fume hood before being moved to a growth chamber overnight ( 8 to $12 \mathrm{~h}$ ).

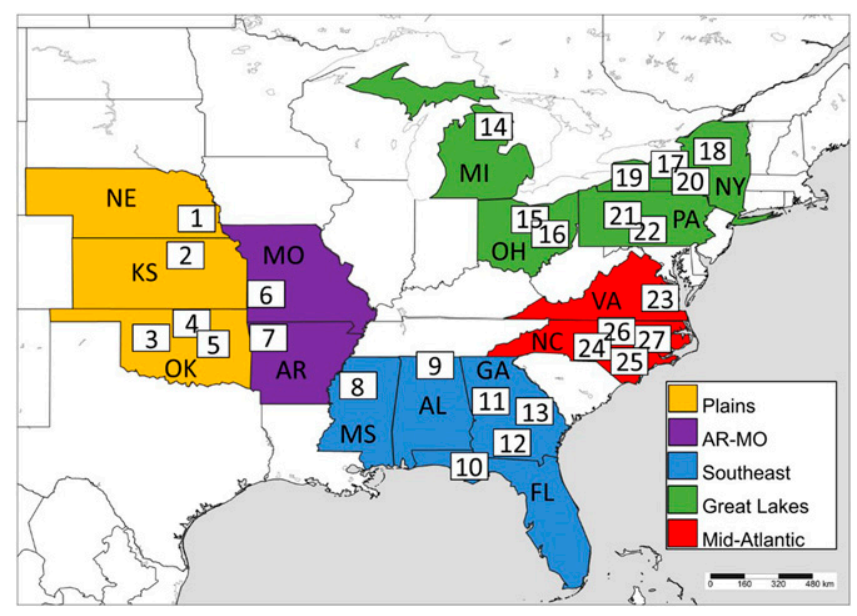

Fig. 1. Map showing approximate locations where samples of wheat with powdery mildew were collected in 2013 and 2014 (numbers indicate fields; see Table 1 for details). States were grouped in five geographic regions based on wheat market class and previous population analyses (Cowger et al. 2016). NE = Nebraska; $\mathrm{KS}=$ Kansas; OK = Oklahoma; $\mathrm{MO}=$ Missouri; $\mathrm{AR}=$ Arkansas; $\mathrm{MS}=$ Mississippi; $\mathrm{AL}=$ Alabama; $\mathrm{FL}=$ Florida; $\mathrm{GA}=$ Georgia; $\mathrm{Ml}=$ Michigan; $\mathrm{OH}=$ Ohio; $\mathrm{NY}=$ New York; PA = Pennsylvania; VA = Virginia; and NC = North Carolina. 
Seedlings to which fungicide had been applied were then cut into leaf segments approximately $3 \mathrm{~cm}$ in length. Four leaf segments sprayed with a given fungicide concentration were floated on benzimidazole-amended (50 mg/liter) $0.5 \%$ water agar in a $60 \times$ $15-\mathrm{mm}$ plastic Petri plate. Twelve plates, one for each fungicide concentration plus the water control, were evenly inoculated with $\mathrm{B}$. graminis f. sp. tritici conidia of a single isolate using a settling tower. Plates were incubated at $17^{\circ} \mathrm{C}$ with $12 \mathrm{~h}$ of light.

Ratings were conducted at 10 days post-inoculation. Leaf segments were rated for fungal growth based on pustule coverage and density. Each leaf segment was rated, producing four ratings per concentration, on a scale of 0 to 3 , where $0=$ no fungal growth, green leaf segment, or one to two sparsely sporulating pustules; $1=$ less than 10 individual pustules covering between 5 and $20 \%$ of the leaf segment; 2 = multiple fluffy individual pustules covering between 20 and $60 \%$; and $3=$ many fluffy, dense, coalescing pustules covering more than $60 \%$ of the leaf segment (Supplementary Fig. 1 ). This detached leaf assay was completed once per $B$. graminis f. sp. tritici isolate $\times$ fungicide concentration combination. In a few cases, particular isolates were in poor condition or unavailable at the time of testing, such that the actual totals of isolates assayed for tebuconazole and prothioconazole sensitivity were 382 and 345, respectively. Hormetic effects (whereby low doses may have a beneficial effect while high doses have an inhibitory one) were not observed (Supplementary Fig. 2).

Measuring sporulation as a component of fitness. In some pathosystems, isolates with reduced sensitivity (or full resistance) to a fungicide exhibit a fitness cost (Mikaberidze and McDonald 2015). Here, we evaluated B. graminis f. sp. tritici isolate sporulation as a quantitative component of fitness. Spores per pustule were quantified by collecting five samples per isolate of about 20 (18 to 22) individual, noncoalescing pustules each.

Detached susceptible ('Chancellor' or 'Jagalene') wheat leaf segments on benzimidazole-amended agar were inoculated lightly, about half of regular inoculation density, to ensure individual pustules could be visually counted and collected. Pustules were collected into tubes of $100 \%$ ethanol at 8 days post-inoculation. Ethanol was then evaporated from the samples using a SpeedVac. Dry, pelleted conidia were resuspended in $100 \mu$ l of pure, white, light mineral oil by vortexing. Using a hemocytometer, the total number of conidia in the 25 innermost squares were counted. The number of spores per sample and the number of spores per pustule were then calculated for each isolate as follows:

$$
\begin{aligned}
\text { spores per sample } & =(\text { number of counted spores }) \times 100,000 \\
\text { spores per pustule } & =\frac{\text { spores per sample }}{\text { number of pustules collected }}
\end{aligned}
$$

The 100,000 in the first formula accounts for both the hemocytometer and the $100-\mu l$ suspension volume. The mean number of spores per pustule for all five collected samples and the standard error of that mean were calculated. In a few cases, isolates died before being evaluated for fitness, such that sporulation data were collected for a total of 364 isolates out of the 382 total isolates.

Effective concentration calculations. Leaf segment ratings were used to calculate relative $\mathrm{EC}_{50}$ values, where $\mathrm{EC}_{50}$ is defined as a parameter estimate of the effective fungicide concentration at which an isolate's growth is inhibited by $50 \%$ (Noel et al. 2018). For this calculation, leaf ratings normalized by 3 , where a rating of 3 represented full, uninhibited growth, acted as the dependent variable, and the natural logarithm of the fungicide concentration for each rating was the independent variable. $\mathrm{EC}_{50}$ values along with standard errors were calculated in SAS 9.4 (SAS Institute, Cary, NC) using a nonlinear mixed model (PROC NLMIXED), where normalized leaf ratings, as a function of fungicide concentration, followed a logistic curve, and the random variation around the predicted curve followed a Gaussian

Table 1. Isolates of Blumeria graminis f. sp. tritici collected during 2013 and 2014 in five United States wheat-growing regions and assayed for tebuconazole

\begin{tabular}{|c|c|c|c|c|c|c|}
\hline Region & Year & Field ${ }^{y}$ & State & Town & Cultivar & $N^{\mathbf{z}}$ \\
\hline Plains & 2014 & 1 & Nebraska & Lincoln & Unknown & 13 \\
\hline Plains & 2014 & 2 & Kansas & Manhattan & 2137 & 19 \\
\hline Plains & 2013 & 3 & Oklahoma & Hinton & Jackpot & 7 \\
\hline Plains & 2013 & 4 & Oklahoma & Stillwater & OK Bullet & 10 \\
\hline Plains & 2014 & 5 & Oklahoma & Stillwater & Pete & 14 \\
\hline AR-MO & 2014 & 6 & Missouri & Bronaugh & MFA2525 & 15 \\
\hline AR-MO & 2014 & 7 & Arkansas & Fayetteville & Ricochet & 13 \\
\hline Southeast & 2013 & 8 & Mississippi & Greenwood & Coker 9553/Armor Ricochet & 20 \\
\hline Southeast & 2014 & 9 & Alabama & Athens & Unknown & 18 \\
\hline Southeast & 2014 & 10 & Florida & Gretna & AGS2060 & 18 \\
\hline Southeast & 2013 & 11 & Georgia & Pine Mountain & Magnolia & 26 \\
\hline Southeast & 2014 & 12 & Georgia & Thomasville & AGS2060 & 14 \\
\hline Southeast & 2014 & 13 & Georgia & Sandersville & AGS2000 & 12 \\
\hline Great Lakes & 2014 & 14 & Michigan & Rogers City & MSU-D6234 & 12 \\
\hline Great Lakes & 2013 & 15 & Ohio & Jeromesville & Croplan 8309 & 20 \\
\hline Great Lakes & 2014 & 16 & Ohio & Wooster & Bravo & 14 \\
\hline Great Lakes & 2013 & 17 & New York & Brockport & Otsego & 9 \\
\hline Great Lakes & 2013 & 18 & New York & Aurora & Pioneer 25R34 & 5 \\
\hline Great Lakes & 2014 & 19 & New York & Brockport & Otsego & 17 \\
\hline Great Lakes & 2014 & 20 & New York & Groveland & Otsego & 13 \\
\hline Great Lakes & 2013 & 21 & Pennsylvania & Pennsylvania Furnace & Growmark 820 & 18 \\
\hline Great Lakes & 2014 & 22 & Pennsylvania & Pennsylvania Furnace & Chemgro DH75 & 14 \\
\hline Mid-Atlantic & 2013 & 23 & Virginia & Saluda & Southern States 8404 & 12 \\
\hline Mid-Atlantic & 2013 & 24 & North Carolina & Four Oaks & Featherstone & 12 \\
\hline Mid-Atlantic & 2013 & 25 & North Carolina & Calypso & Coker Oakes & 15 \\
\hline Mid-Atlantic & 2014 & 26 & North Carolina & Clayton & USG 3120 & 15 \\
\hline Mid-Atlantic & 2014 & 27 & North Carolina & Mt. Olive & Coker Oakes & 11 \\
\hline
\end{tabular}
sensitivity, prothioconazole sensitivity, and sporulation

y Approximate field locations are shown in Figure 1.

${ }^{\mathrm{z}} N=$ maximum number of isolates assayed per field. For 16 field $\times$ assay combinations, there were missing data for one to four isolates, such that a total of 378 isolates were analyzed for tebuconazole sensitivity, 369 for prothioconazole sensitivity, and 364 for sporulation. 
distribution (Kiernan et al. 2012). The logistic curve equation was given as follows:

$$
y_{i}=\frac{1}{1+\left(\frac{1}{b_{o}}-1\right) \exp \left(-b_{1} \text { conc }\right)}
$$

and the $\mathrm{EC}_{50}$ was calculated as follows:

$$
\text { estimated } \mathrm{EC}_{50}=\frac{\log \left(\frac{1}{\frac{1}{b_{o}}-1}\right)}{-b_{1}}
$$

This model required that $b_{0}$ be greater than zero and $b_{1}$ be negative. Most $\mathrm{EC}_{50}$ value estimates were calculated using the SAS NLMIXED model with default settings. However, approximately 40 prothioconazole $\mathrm{EC}_{50}$ values required fine tuning of the settings by increasing the maximum number of iterations, changing the integration method, or changing the optimization technique. When using the default settings, these $\mathrm{EC}_{50}$ values were estimated with low precision and were not significantly different from zero, because the estimated values fell in a relatively large gap between measured fungicide concentrations (e.g., between 40 and $80 \mathrm{mg} / \mathrm{liter}$ of prothioconazole).

Reproducibility of the assay was verified by repeating it once each for 50 isolates for tebuconazole and 47 isolates for prothioconazole (Supplementary Fig. 3). The calculated $\mathrm{EC}_{50}$ values of the analytical replicates were ranked and converted into normal quantiles (on a 0 to-1 scale) using the SAS 9.4 RANK procedure; because of skew, the Blom rank transformation option was applied to normalize the $\mathrm{EC}_{50}$ values and stabilize variances. The CORR procedure was then used to evaluate the rank concordance of the two replicates. For both DMIs, significant correlation coefficients confirmed that the assay was able to rank isolates reproducibly across the $\mathrm{EC}_{50}$ range (tebuconazole: $P<0.0001$, Spearman $S=0.66$; prothioconazole: $P=0.0001$, $S=0.54)$.

Geographical comparisons. $\mathrm{EC}_{50}$ values were compared at the three hierarchical geographic sampling levels (region, state, and field) for each fungicide using a generalized linear mixed model (PROC GLIMMIX), a log normal distribution, and the KenwardRoger method for calculating denominator degrees of freedom in the testing of type III hypotheses of no effect. Tebuconazole and prothioconazole $\mathrm{EC}_{50}$ values were the dependent variables, and region, state nested within region, and field nested within state and region were the independent variables. Collections from multiple fields were not available in all 15 states; however, both state- and field-level variables were included to account for variation among fields when evaluating at the field level. States represented by a single field did not contribute to the estimation of the effect of field nested within state and region. Least square mean estimates of $\mathrm{EC}_{50}$ values were compared at each of the three sampling levels per DMI fungicide. Sporulation values were compared using the same PROC GLIMMIX model with spores per pustule as the dependent variable and region, state, and field as independent variables.

The possible presence of cross-resistance to tebuconazole and prothioconazole (isolates having diminished sensitivity to both DMIs), as well as correlation of $\mathrm{EC}_{50}$ of each fungicide with sporulation, were evaluated using a general linear model (PROC GLM) multivariate analysis of variance. In that analysis, region, state nested within region, and field nested within state and region were the experimental factors. $\mathrm{EC}_{50}$ values and spores per pustule, the dependent variables, were log transformed to improve homogeneity of variances, and the experimental factors were used to determine the residuals for each dependent variable and calculate the partial correlation between the sets of residuals. Partial correlation coefficients from the error terms were used for correlation analysis after accounting for the experimental effects.

\section{Results}

Range in $\mathbf{E C}_{50}$ value compared with European controls. Observed tebuconazole $\mathrm{EC}_{50}$ values for the U.S. isolates ranged from $0.12( \pm 0.02) \mathrm{mg} / \mathrm{liter}$ to $18.7( \pm 3.0) \mathrm{mg} / \mathrm{liter}$, a 155 -fold difference in tebuconazole sensitivity, with a median value of $1.2 \mathrm{mg} /$ liter (Supplementary Fig. 4). The two European control isolates ranked as expected relative to each other but with only a 2-fold difference in tebuconazole sensitivity: the DMI-resistant isolate Fel09 had a high $\mathrm{EC}_{50}$ value relative to the observed U.S. sensitivity range at $13.9( \pm 1.0)$ $\mathrm{mg} / \mathrm{liter}$, and DMI-sensitive isolate JIW11 had an $\mathrm{EC}_{50}$ of 7.1 $( \pm 1.3) \mathrm{mg} / \mathrm{liter}$. Both European isolates were above the U.S. median and above the U.S. third quartile value of $2.4 \mathrm{mg} / \mathrm{liter}$.

Among the U.S. isolates, observed prothioconazole $\mathrm{EC}_{50}$ values ranged from $0.19( \pm 0.09) \mathrm{mg} / \mathrm{liter}$ to $295.7( \pm 86.2) \mathrm{mg} / \mathrm{liter}$, a 1,556-fold difference with a median value of $32.6 \mathrm{mg} / \mathrm{liter}$. Again, there was a much smaller (58-fold) difference in prothioconazole sensitivity between the two European control isolates, although these isolates ranked as expected: DMI-resistant isolate Fel09 had a prothioconazole $\mathrm{EC}_{50}$ value of $463.0( \pm 37.6) \mathrm{mg} / \mathrm{liter}$, and DMI-sensitive isolate JIW11 had an $\mathrm{EC}_{50}$ of $8.0( \pm 4.8) \mathrm{mg} / \mathrm{liter}$. The Fel09 value exceeded the observed prothioconazole U.S. range, whereas the value for JIW11 was below the first quartile, $16.3 \mathrm{mg} / \mathrm{liter}$.

Geographic differences in DMI sensitivity. Significant differences in mean regional $\mathrm{EC}_{50}$ values were detected for both DMIs (Fig. 2). A higher $\mathrm{EC}_{50}$ value indicates a reduction in fungicide sensitivity. Eastern regional populations (Mid-Atlantic, Southeast, and Great Lakes) had significantly higher mean tebuconazole $\mathrm{EC}_{50}$ values than central regional populations (AR-MO and Plains)
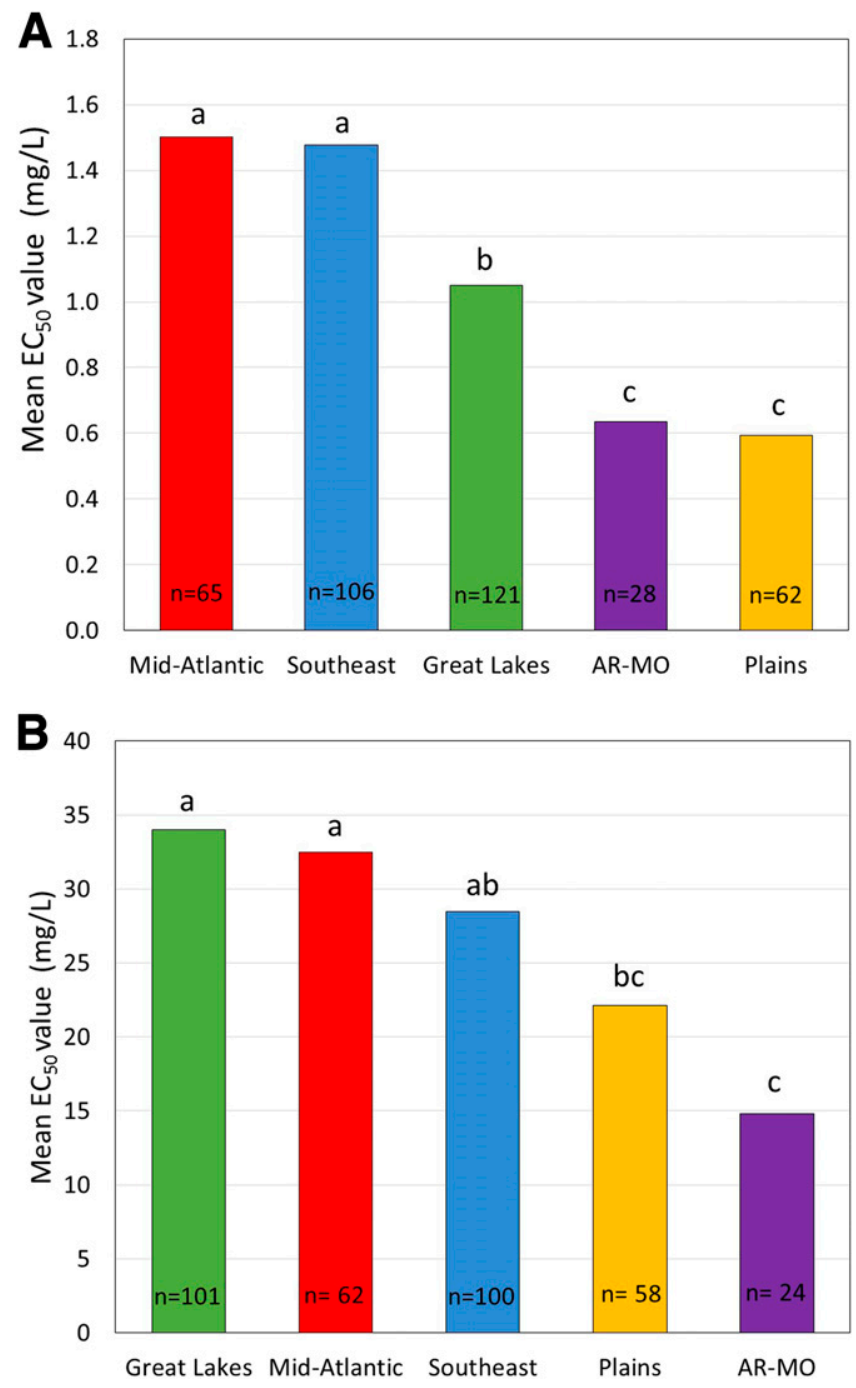

Fig. 2. Regional mean $\mathrm{EC}_{50}$ values of tebuconazole (A) and prothioconazole (B). Sample sizes per region are shown in each bar. Bars topped by the same letter are not significantly different $(P<0.05)$ using a pairwise $t$ test. 
$(P<0.0001)$ (Fig. 2A). Among the eastern populations, the MidAtlantic and Southeast regions were also significantly higher in $\mathrm{EC}_{50}$ than the Great Lakes region. Isolates from Georgia, New York, and Mississippi exhibited a large and significant reduction in tebuconazole sensitivity (Table 2). Isolates from North Carolina and Virginia also had reduced sensitivity compared with isolates originating from the most sensitive states: Michigan, Nebraska, Oklahoma, and Missouri $(P<0.0001)$ (Table 2). At the field level, the most tebuconazole-insensitive populations were sampled from fields 11 and 12 in Georgia, field 19 in New York, and field 27 in North Carolina (Table 3). Isolates collected from field 6 in Missouri, field 1 in Nebraska, and fields 4 and 5 in Oklahoma were most sensitive to tebuconazole $(P<0.0001)$.

Within the geographic regions, there were some significant differences in tebuconazole sensitivity between states within a region (Table 2) and between fields within a state (Table 3). The differences were overall less in the central U.S. states: Arkansas isolates exhibited significantly more insensitivity than Missouri isolates, and there were no significant differences among the Plains states of Kansas, Nebraska, and Oklahoma (Table 2) or among the three Oklahoma fields (Table 3). By contrast, in the Southeast region, Georgia isolates were more tebuconazole insensitive than Florida and Alabama isolates, and Mississippi isolates were more insensitive than Florida isolates. Within Georgia, fields 11 and 12 were significantly more insensitive than field 13. In the Great Lakes region, New York isolates were significantly more insensitive than Ohio, Pennsylvania, and Michigan isolates, and there were several field-to-field differences within New York and Ohio. Mid-Atlantic states were not significantly different from each other; however, within North Carolina, field 27 was significantly more tebuconazole insensitive than all other North Carolina fields.

The same east-west difference observed for tebuconazole sensitivity was detected in regional mean prothioconazole $\mathrm{EC}_{50}$ values $(P=$ 0.0001 ) (Fig. 2B). Isolates from the Great Lakes, Mid-Atlantic, and Southeast regions had significantly higher $\mathrm{EC}_{50}$ values than those from the AR-MO region, and isolates from the Plains were significantly more sensitive than Great Lakes and Mid-Atlantic isolates (Fig. 2B). Reduced prothioconazole sensitivity was prominent in Georgia, New York, and North Carolina as well as Ohio, Arkansas, and Kansas $(P<0.0001)$ (Table 2$)$. Much like tebuconazole, state populations most sensitive to prothioconazole were in Oklahoma, Nebraska, and Missouri. As with tebuconazole, Georgia fields 11 and 12 and New York field 19 exhibited significant reduction in sensitivity to prothioconazole (Table 3) compared with the most sensitive fields. In this case, they were joined by New York fields 18 and 20, Ohio field 16, and North Carolina field 26. The fields most sensitive to prothioconazole were again Missouri field 6, Nebraska field 1, and Oklahoma fields 4 and 5, as well as New York field 17 $(P=0.0013)$.

There were also differences in prothioconazole sensitivity within regions (Table 2) and states (Table 3). In the Plains region, Kansas was significantly more insensitive than Nebraska and Oklahoma, whereas no Oklahoma fields were significantly different from one another. As with tebuconazole, Arkansas isolates exhibited significantly more prothioconazole insensitivity than Missouri isolates and, in the Southeast, Georgia isolates were significantly more insensitive than Florida and Alabama isolates. In Georgia, fields 11 and 12 were more insensitive than field 13, and in North Carolina field 26 was significantly more insensitive than field 25. In the Great Lakes, New York and Ohio isolates were significantly more prothioconazole insensitive than Michigan isolates, whereas Mid-Atlantic states were not significantly different from each other.

Sporulation variability and relationship to DMI sensitivity. Sporulation was successfully quantified for 364 of the U.S. isolates screened for DMI sensitivity. Among isolates, sporulation ranged from 1,000 spores per pustule, the lower limit of the spore quantification method, to 636,658 spores per pustule. Geographic differences in sporulation were significant $(P=0.0014)$ at the state level (Table 2). On average, isolates from New York, Mississippi, and
Nebraska produced significantly more spores per pustule than isolates from Georgia, Virginia, Pennsylvania, North Carolina, and Ohio. Sporulation was not significantly different at the regional $(P=0.12)$ or field $(P=0.38)$ levels (data not shown).

Table 2. Mean tebuconazole and prothioconazole sensitivities and sporulation of Blumeria graminis f. sp. tritici isolates sampled in 2013 to 2014 from 15 U.S. statesw

\begin{tabular}{|c|c|c|c|c|}
\hline \multirow[b]{2}{*}{ State } & \multirow[b]{2}{*}{$N^{\mathbf{x}}$} & \multicolumn{2}{|c|}{$\mathrm{EC}_{50}{ }^{\mathrm{y}}$} & \multirow[b]{2}{*}{ Sporulation $^{z}$} \\
\hline & & Tebuconazole & Prothioconazole & \\
\hline Georgia & 51 & $2.52 \mathrm{a}$ & $44.74 \mathrm{ab}$ & $25,132 \mathrm{a}$ \\
\hline New York & 42 & $2.01 \mathrm{ab}$ & $48.18 \mathrm{a}$ & $64,854 \mathrm{~cd}$ \\
\hline Mississippi & 20 & $1.82 \mathrm{abc}$ & $28.67 \mathrm{bcd}$ & $72,446 \mathrm{~cd}$ \\
\hline North Carolina & 53 & $1.66 \mathrm{bc}$ & $39.80 \mathrm{ab}$ & $37,718 \mathrm{ab}$ \\
\hline Virginia & 12 & $1.36 \mathrm{bcd}$ & 26.51 abcde & $30,209 \mathrm{ab}$ \\
\hline Alabama & 18 & $1.20 \mathrm{cde}$ & $22.05 \mathrm{cde}$ & $61,445 \mathrm{bcd}$ \\
\hline Ohio & 35 & 0.97 def & $46.25 \mathrm{ab}$ & $38,330 \mathrm{ab}$ \\
\hline Pennsylvania & 32 & 0.96 def & $30.04 \mathrm{abcd}$ & $37,142 a b$ \\
\hline Arkansas & 13 & $0.89 \mathrm{def}$ & $42.81 \mathrm{abc}$ & 49,183 abcd \\
\hline Florida & 18 & $0.86 \mathrm{def}$ & $23.26 \mathrm{cde}$ & $56,562 \mathrm{bcd}$ \\
\hline Kansas & 19 & $0.75 \mathrm{defg}$ & $36.35 \mathrm{abc}$ & $42,719 \mathrm{abc}$ \\
\hline Michigan & 12 & $0.65 \mathrm{efg}$ & $20.01 \mathrm{cde}$ & $51,606 \mathrm{bcd}$ \\
\hline Nebraska & 13 & $0.57 \mathrm{fg}$ & $14.84 \mathrm{e}$ & $98,037 \mathrm{~d}$ \\
\hline Oklahoma & 31 & $0.49 \mathrm{~g}$ & $20.04 \mathrm{de}$ & $53,162 \mathrm{bcd}$ \\
\hline Missouri & 15 & $0.45 \mathrm{~g}$ & $5.12 \mathrm{f}$ & 57,240 bcd \\
\hline
\end{tabular}

${ }^{w}$ Within a column, means followed by the same letter are not significantly different at $P<0.05$ using a pairwise $t$ test.

x $N=$ maximum number of isolates assayed per state.

y $\mathrm{EC}_{50}=$ effective concentration of fungicide at which isolate growth is decreased by $50 \%$. Mean $\mathrm{mg} /$ liter of fungicide active ingredient.

z Mean spores per pustule.

Table 3. Mean tebuconazole and prothioconazole phenotypic sensitivity values of Blumeria graminis f. sp. tritici isolates per field sampled in 2013 to $2014^{x}$

\begin{tabular}{|c|c|c|c|c|}
\hline \multirow[b]{2}{*}{ State } & \multirow[b]{2}{*}{ Field } & \multirow[b]{2}{*}{$N^{\mathbf{y}}$} & \multicolumn{2}{|c|}{$\mathrm{EC}_{50}{ }^{\mathrm{z}}$} \\
\hline & & & Tebuconazole & Prothioconazole \\
\hline Georgia & 11 & 26 & $4.24 \mathrm{a}$ & $50.22 \mathrm{abc}$ \\
\hline North Carolina & 27 & 11 & $3.50 \mathrm{ab}$ & 49.01 abcefg \\
\hline New York & 19 & 17 & $3.39 \mathrm{ab}$ & $76.14 \mathrm{ab}$ \\
\hline Georgia & 12 & 13 & $3.13 \mathrm{abc}$ & $70.53 \mathrm{abc}$ \\
\hline New York & 20 & 13 & $2.14 \mathrm{bcd}$ & $77.82 \mathrm{ab}$ \\
\hline Mississippi & 8 & 19 & $1.82 \mathrm{~cd}$ & 28.67 defghij \\
\hline North Carolina & 24 & 12 & 1.65 cde & 39.18 abcdefgh \\
\hline New York & 18 & 5 & 1.52 bcdef & $56.33 \mathrm{abcd}$ \\
\hline Ohio & 16 & 15 & $1.51 \mathrm{deg}$ & 50.56 abcef \\
\hline New York & 17 & 9 & 1.48 defg & $16.15 \mathrm{ijk}$ \\
\hline North Carolina & 26 & 15 & $1.47 \mathrm{deg}$ & 52.44 abce \\
\hline Virginia & 23 & 12 & $1.36 \mathrm{degh}$ & 26.51 defghijk \\
\hline Pennsylvania & 22 & 14 & 1.22 defgh & 40.31 abcdefghi \\
\hline Georgia & 13 & 12 & 1.21 defgh & 25.28 dfghijk \\
\hline Alabama & 9 & 18 & 1.20 defgh & 22.05 hijk \\
\hline Arkansas & 7 & 13 & 0.89 efghi & 42.81 abcdefgh \\
\hline North Carolina & 25 & 15 & 0.88 efghi & 24.91 dghijk \\
\hline Florida & 10 & 18 & 0.86 fghi & 23.26 dghijk \\
\hline Kansas & 2 & 19 & 0.75 fhij & 36.35 cdefgh \\
\hline Pennsylvania & 21 & 18 & 0.75 fhij & 22.38 dhijk \\
\hline Michigan & 14 & 12 & $0.65 \mathrm{fij}$ & 20.01 hijk \\
\hline Oklahoma & 3 & 7 & 0.65 fhijk & 29.80 bcdefghik \\
\hline Ohio & 15 & 20 & $0.62 \mathrm{ij}$ & 42.30 abcefg \\
\hline Nebraska & 1 & 13 & $0.57 \mathrm{ijk}$ & $14.84 \mathrm{k}$ \\
\hline Oklahoma & 4 & 10 & $0.54 \mathrm{ijk}$ & $16.99 \mathrm{ijk}$ \\
\hline Missouri & 6 & 15 & $0.45 \mathrm{jk}$ & 5.121 \\
\hline Oklahoma & 5 & 14 & $0.33 \mathrm{k}$ & $15.89 \mathrm{jk}$ \\
\hline
\end{tabular}

${ }^{x}$ Within a column, means followed by the same letter are not significantly different at $P<0.05$ using a pairwise $t$ test.

y $N=$ maximum number of isolates assayed per field.

${ }^{\mathrm{z}} \mathrm{EC}_{50}=$ effective concentration of fungicide at which isolate growth is decreased by $50 \%$. Mean $\mathrm{mg} / \mathrm{liter}$ of fungicide active ingredient. 
At the geographic level of state, for which sporulation differed significantly, the correlation of sporulation to prothioconazole sensitivity was significant but weak (Fig. 3). State mean prothioconazole $\mathrm{EC}_{50}$ values were significantly negatively correlated with state mean spores per pustule, but with a low $r$ value of $-0.12(P=0.03)$. The same relationship was found to be significant at the field level $(r=$ $-0.15, P=0.01)$ but was not significant at the regional $(r=-0.08$, $\mathrm{P}=0.15)$ or isolate $(r=-0.02, P=0.89)$ levels (data not shown). No significant relationships between tebuconazole $\mathrm{EC}_{50}$ values and sporulation were identified.

Cross-resistance to DMIs. The results showed evidence of crossresistance to tebuconazole and prothioconazole (Fig. 4). The $\mathrm{EC}_{50}$ values for the two DMIs were significantly associated at all four geographic levels: isolate $(r=0.36, P=0.0344)$, field $(r=0.46, P<$ $0.0001)$, state $(r=0.47, P<0.0001)$, and region $(r=0.53, P<$ $0.0001)$.

\section{Discussion}

Along with resistant wheat cultivars and another chemistry class (quinone outside inhibitors), DMI fungicides are presently one of just three tools for controlling epidemics of $B$. graminis $\mathrm{f}$. sp. tritici. In the U.S., epidemics of wheat powdery mildew have expanded to new areas of the country in recent years, where commercial varieties tend to be susceptible because resistance to the disease has historically not been a breeding priority. Taken together, these facts highlight the need to quantify the current efficacy of, monitor, and protect available wheat powdery mildew control measures. However, although DMI fungicides have been registered on wheat for over 20 years in the U.S., this is the first study to monitor the sensitivity of the U.S. B. graminis f. sp. tritici population to any members of this chemistry class.

Our results reveal regional differences in sensitivity; however, without an earlier baseline of U.S. B. graminis f. sp. tritici DMI sensitivity for comparison, we can only infer that local populations with reduced sensitivity are in the early stages of developing resistance due to adaptation by the fungal population. Compared with sensitivity of B. graminis f. sp. tritici populations in Europe, no portion of the U.S. population is strongly insensitive to either fungicide tested here, and the focus now should be on preserving the DMI efficacy that remains.

We observed a large range in $B$. graminis $\mathrm{f}$. sp. tritici sensitivity to both tebuconazole and prothioconazole across the central and eastern U.S. The east-west divide in sensitivity to both DMIs is further evidence that B. graminis f. sp. tritici in the U.S. is not one large random-mating population, but instead consists of multiple subpopulations with isolate migration only occurring from west to east (Cowger et al. 2016). The same regional pattern was observed in virulence to wheat $P m$ genes in a study that included the isolates used here (Cowger et al. 2018).

The DMI sensitivity that we identified in the western part of our sampling area was as hypothesized. However, we expected DMI insensitivity to be maximal in the Mid-Atlantic region owing to the greater frequency of epidemics there, and instead, reduced sensitivity

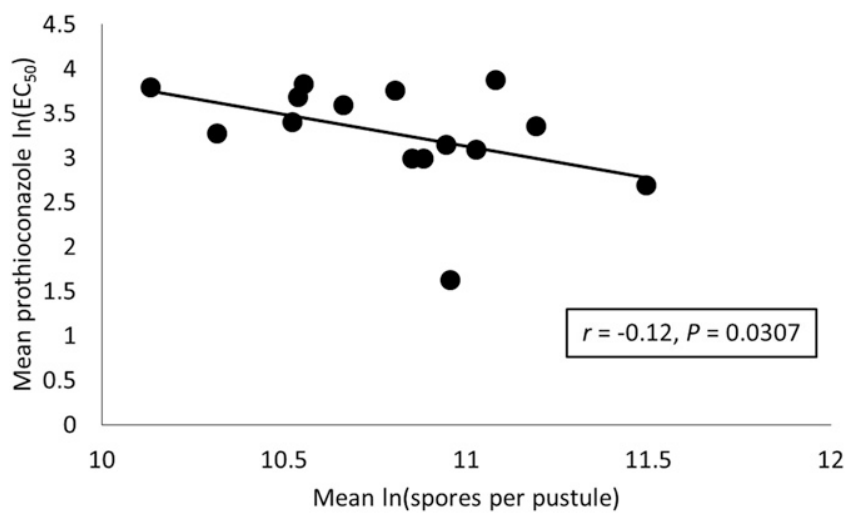

Fig. 3. Correlation of mean log-transformed prothioconazole $E_{50}$ values with Blumeria graminis f. sp. tritici sporulation, a component of fitness; each data point is a state mean spanned the entire eastern U.S. wheat-growing area. This can be partially explained by the previously observed genetic similarity of the Mid-Atlantic and Great Lakes B. graminis f. sp. tritici populations (Cowger et al. 2016). Together with previous findings on migration patterns of U.S. B. graminis f. sp. tritici (Cowger et al. 2016), our results suggest that the $B$. graminis f. sp. tritici populations of the Plains and AR-MO regions will likely remain sensitive to DMI fungicides due to migration, because sensitive isolates may migrate from there to the Southeast, Great Lakes, and Mid-Atlantic regions, but less sensitive isolates should not migrate from those areas toward the west.

Although regional populations did have characteristic and significantly different DMI sensitivity levels, there were also significant differences between states in a region and between fields in a state. This was least apparent in the Plains, where genetic diversity for DMI sensitivity is relatively low and fungicide applications to wheat are less frequent than in the eastern U.S. By contrast, there were more sensitivity differences within other regions. For example, significant differences in sensitivity to both DMIs were observed between fields in Georgia and North Carolina, where collection sites were within 175 and 50 miles, respectively, of each other. These local differences support the isolation-by-distance model of many small, separate yet intermixing B. graminis f. sp. tritici populations in the U.S. (Cowger et al. 2016). Altogether, our results suggest there is greater diversity in DMI sensitivity in the eastern U.S. states, providing the opportunity for more rapid gain in insensitivity through selection.

Our findings suggest that central U.S. B. graminis f. sp. tritici populations have had relatively less exposure to tebuconazole and prothioconazole. More frequent exposure is likely occurring in eastern populations, particularly those in New York, North Carolina, and Georgia fields, and is producing a selective effect in the form of reduced sensitivity. The regional differences observed here are consistent with fungicide application data collected by the U.S. Geological Survey (USGS). Over the years of tebuconazole use, heavy application across all crops was reported in southern Alabama, Georgia, Florida, North Carolina, southern Virginia, western New York, and Ohio (Baker and Stone 2015; Thelin and Stone 2013). This fits with the reduction in tebuconazole sensitivity observed in our study. However, tebuconazole use in Kansas and Oklahoma increased greatly in 2010 to 2012 (Baker and Stone 2015) and in preliminary data in 2013 and 2014, the years leading up to collection of the present sample (https://water.usgs.gov/nawqa/pnsp/usage/maps/show_map.php? year $=2013 \&$ map $=$ TEBUCONAZOLE\&hilo=L). This increase was not reflected in the performance of our $B$. graminis $\mathrm{f}$. sp. tritici isolates from those Great Plains states. Due to low wheat powdery mildew incidence in these states during collection years 2013 and 2014, we had relatively few fields and isolates to represent the Plains region. Perhaps a more extensive sample in the future might reflect the effects of this increase in tebuconazole use. In the USGS fungicide use survey, prothioconazole use across crops was highest in Georgia, Florida, North Carolina, Virginia, and Ohio (Baker and Stone 2015;

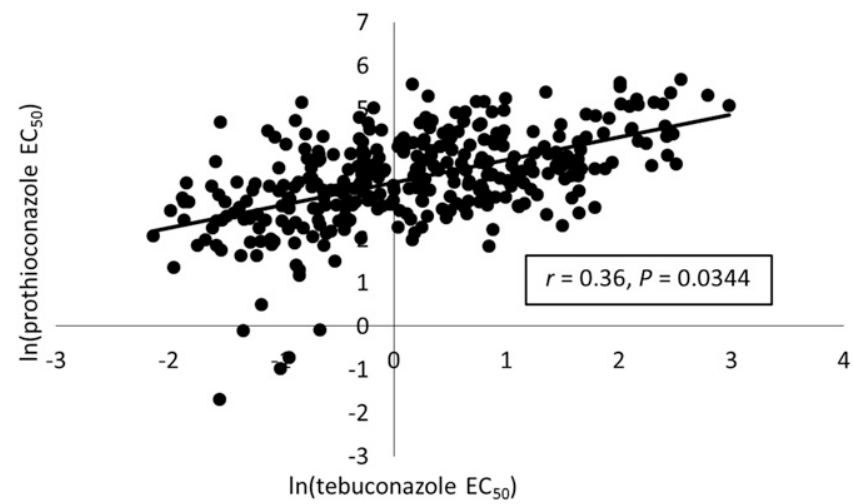

Fig. 4. Correlation of log-transformed sensitivity $\left(E C_{50}\right)$ to tebuconazole and prothioconazole in U.S. Blumeria graminis f. sp. tritici isolates. 
Thelin and Stone 2013). This is consistent with the decrease in prothioconazole sensitivity our study found in Georgia, North Carolina, and Ohio.

A degree of cross-resistance was suggested by the correlation of tebuconazole and prothioconazole $\mathrm{EC}_{50}$ values at all geographic levels. Although significant, the association was weak; indeed, several outlier isolates exhibited highly reduced sensitivity to one of the fungicides while remaining fully sensitive to the other. These results suggest that $B$. graminis f. sp. tritici adapts to overcome DMIs via two or more different mechanisms. In this case, there may be a shared pathway that increases both tebuconazole and prothioconazole insensitivity, but also one or more additional mechanisms that specifically enhance resistance to one of the active ingredients.

Tebuconazole and prothioconazole molecules likely do not interact with $B$. graminis f. sp. tritici using the same mechanism, because prothioconazole itself is a triazolinthione, whereas tebuconazole is a triazole. The antifungal effects of prothioconazole are owing to its primary metabolite, prothioconazole-desthio (Parker et al. 2013). Prothioconazole-desthio is a true triazole and binds the same target protein in the ergosterol synthesis pathway as other DMIs (Parker et al. 2013; Price et al. 2015). Perhaps this chemical difference in the two DMIs requires $B$. graminis $\mathrm{f}$. sp. tritici to utilize multiple pathways to become insensitive to both fungicides. Despite this chemical difference and the 10-year difference in registration in the U.S., the geographic and individual patterns of insensitivity to tebuconazole and prothioconazole are similar. This finding was surprising, because we expected more insensitivity to the older product, tebuconazole, than the newer prothioconazole. Given that crossresistance is present, the years of tebuconazole use (and perhaps the use of other older DMI fungicides) may have primed B. graminis f. sp. tritici isolates for reduced prothioconazole sensitivity before the latter was ever applied. However, without a true baseline for B. graminis $\mathrm{f}$. sp. tritici prothioconazole sensitivity at the start of its commercial use on U.S. wheat, there is no way to know whether this priming hypothesis is correct.

In gaining the ability to overcome a fungicide, pathogen isolates may pay a fitness cost. Fitness is complex, being determined by many factors; therefore, we expected to observe a large variation in sporulation among isolates, and we did. Among states and isolates, sporulation was significantly associated with sensitivity to prothioconazole, but with very low correlation values. This weak relationship was presumably owing to the influence of variables other than DMI sensitivity on sporulation capacity. Thus, the effect of reduced prothioconazole sensitivity on B. graminis f. sp. tritici fitness, if any, appears to be very small in proportion to overall isolate-to-isolate variation. Isolates from Georgia, Virginia, North Carolina, and Ohio exhibited reduced DMI sensitivity and relatively low spore production, but isolates from other states that also had reduced prothioconazole sensitivity, such as New York and Mississippi, had very high spore production (Table 2). This indicates that prothioconazole insensitivity in B. graminis f. sp. tritici is not necessarily accompanied by a measurable reduction in fitness, or the effect is so mild that it is overshadowed by other fitness determinants. Of course, other fitness components not assayed in this study could be affected by reduced DMI sensitivity.

Tebuconazole $\mathrm{EC}_{50}$ values did not significantly correlate with spore production at any geographic level of analysis, indicating that tebuconazole insensitivity does not engender a fitness cost associated with sporulation in U.S. B. graminis f. sp. tritici populations. Because tebuconazole has been applied to U.S. wheat for 10 more years than prothioconazole, perhaps tebuconazole insensitivity was originally accompanied by a fitness reduction that later compensatory mutations allowed $B$. graminis f. sp. tritici populations to overcome while maintaining tebuconazole insensitivity.

The European B. graminis f. sp. tritici isolates Fel09 and JIW11 were used as DMI-insensitive and DMI-sensitive isolates, respectively, for comparison with U.S. isolates. Although no prior information was available on their sensitivity to tebuconazole and prothioconazole, both isolates had been included in a study evaluating triadimenol and propiconazole sensitivity along with sequencing to identify the genetic basis of DMI insensitivity (Wyand and Brown 2005). Unsurprisingly, Fel09 ranked among the most insensitive U.S. isolates for both DMIs, actually exceeding the highest prothioconazole $\mathrm{EC}_{50}$ value observed in the U.S. collection. JIW11 exhibited a relatively low prothioconazole $\mathrm{EC}_{50}$ value when compared with the range of U.S. values but, surprisingly, performed similarly to the most tebuconazole-insensitive U.S. isolates. These findings suggest that on the whole, the present U.S. B. graminis f. sp. tritici population has remained more sensitive to DMIs than European populations were in the mid-1980s, especially to tebuconazole. This makes sense, given the lower per-hectare application of fungicides to cereals in the U.S. compared with the United Kingdom and Europe.

In summary, we found evidence of reduced DMI sensitivity in eastern U.S. B. graminis f. sp. tritici, probably the result of selection, as well as evidence of a degree of DMI cross-resistance. Although there was some indication of lower sporulation in populations with reduced prothioconazole sensitivity, the effect was very small, and therefore unlikely to substantially affect reproduction of prothioconazole-insensitive isolates. The $B$. graminis f. sp. tritici population of the eastern U.S. soft wheat region appears to be at particular risk of evolving even greater DMI insensitivity. These results support a strategy of chemistry rotation for control of common fungal diseases in eastern U.S. wheat and crops rotated with it. To preserve current DMI efficacy, U.S. wheat growers should continue to rotate DMIs with other chemistries, and use mixed mode of action fungicide products, to lessen the selection pressure imposed on the $\mathrm{B}$. $\mathrm{gra}$ minis f. sp. tritici population (van den Bosch et al. 2014).

Moreover, with a high potential for evolution in B. graminis $\mathrm{f}$. sp. tritici and evidence of fungicide resistance in European $B$. graminis populations starting more than 20 years ago, the U.S. B. graminis $\mathrm{f}$. sp. tritici population should be regularly evaluated for fungicide efficacy. The results of this study can be used as a basis against which to compare DMI sensitivity of future U.S. collections of $B$. graminis f. sp. tritici isolates. This first-ever screening of DMI fungicide sensitivity in U.S. B. graminis f. sp. tritici isolates has demonstrated the need for fungicide recommendations to be made on a regional rather than national level and for greater attention to chemistry rotation and mixing. The earlier that insensitivity is detected in a fungal pathogen population and adjustments to application regimes are made, the more the development of resistance can be slowed (Zulak et al. 2018).

Understanding the molecular basis of DMI insensitivity is important for helping prevent the development of full DMI resistance. $\mathrm{Mu}-$ tations correlating with DMI insensitivity have been identified in both European and Australian B. graminis isolate populations. DMIs slow fungal growth by occupying the active site of the $14 \alpha$-demethylase enzyme (CYP51) and thus not allowing enough ergosterol to be created to support fungal growth (Gisi et al. 2000). For B. graminis $\mathrm{f}$. sp. tritici, the CYP51 gene of DMI-insensitive isolate Fel09 was sequenced by Wyand and Brown (2005) and found to have a Y136F amino acid mutation that was not found in CYP51 of the DMIsensitive isolate, JIW11. Y136F is the most common mutation associated with DMI resistance in many fungi and is the only CYP51 mutation that has been documented in $B$. graminis $\mathrm{f}$. sp. tritici thus far. DMI-insensitive B. graminis f. sp. hordei isolates were found to have the Y136F mutation as well as a K147Q mutation (Wyand and Brown 2005). More recently, an S509T mutation in CYP51 was found, always in combination with $\mathrm{Y} 136 \mathrm{~F}$, in DMI-insensitive Australian B. graminis f. sp. hordei isolates (Tucker et al. 2015). $B$. graminis f. sp. hordei isolates with the S509T mutation exhibited the greatest insensitivity to tebuconazole in particular (Tucker et al. 2015), whereas an S524T mutation (homologous to S509T in B. graminis) in the CYP51 gene of another wheat pathogen, Zymoseptoria tritici, was more closely associated specifically with prothioconazole insensitivity (Cools and Fraaije 2013).

Although the Y136F and S509T mutations are common causes of DMI insensitivity in phytopathogens, many other genetic abnormalities have been linked to DMI resistance. Various influential singlesite mutations have been identified in the CYP51 gene of $Z$. tritici, 
including L50S, D134G, V136A, and Y461S (Becher and Wirsel 2012; Cools and Fraaije 2013; Cools et al. 2011). Other causes besides single nucleotide polymorphisms in CYP51 include an insertion in the promoter region of CYP51 (Garcia-Effron et al. 2008; Hamamoto et al. 2000; Ma et al. 2006; Schnabel and Jones 2001; Villani et al. 2016), which is sometimes linked to overexpression of CYP51 (Hamamoto et al. 2000; Ma et al. 2006; Rallos and Baudoin 2016; Villani et al. 2016), as well as overexpression of efflux drug transporters such as ATP-binding cassette transporters and major facilitator superfamily pumps (Cannon et al. 2009; Leroux and Walker 2011).

With these possible mechanisms of reduced DMI sensitivity in mind, the U.S. B. graminis f. sp. tritici collection used in this phenotypic fungicide sensitivity study is currently under genetic analysis. Efforts focus on identifying mutations in CYP51 or expression differences that may be correlated with reduced sensitivity to tebuconazole and prothioconazole.

\section{Acknowledgments}

We thank E. Cole, M. Hargrove, R. Parks, and G. Supino for excellent technical assistance and $\mathrm{R}$. Whetten for helpful review of the manuscript.

\section{Literature Cited}

Baker, N. T., and Stone, W. W. 2015. Estimated annual agricultural pesticide use for counties of the conterminous United States, 2008-12. U.S. Geological Survey Data Series 907.

Becher, R., and Wirsel, S. G. R. 2012. Fungal cytochrome P450 sterol $14 \alpha-$ demethylase (CYP51) and azole resistance in plant and human pathogens. Appl. Microbiol. Biotechnol. 95:825-840.

Blatter, R. H. E., Brown, J. K. M., and Wolfe, M. S. 1998. Genetic control of the resistance of Erysiphe graminis f. sp. hordei to five triazole fungicides. Plant Pathol. 47:570-579.

Both, M., and Spanu, P. 2004. Blumeria graminis f. sp. hordei, an obligate pathogen of barley. Pages 202-218 in: Plant Pathogen Interactions. N. Talbot, ed. Blackwell Publishing, Oxford, U.K.

Bowen, K. L., Everts, K. L., and Leath, S. 1991. Reduction in yield of winter wheat in North Carolina due to powdery mildew and leaf rust. Phytopathology 81: 503-511.

Brent, K. J., and Hollomon, D. W. 2007. Fungicide Resistance in Crop Pathogens: How Can It Be Managed? 2nd ed. Fungicide Resistance Action Committee, Croplife International, Brussels, Belgium.

Brown, J. K. M., Jessop, A. C., and Rezanoor, H. N. 1991. Genetic uniformity in barley and its powdery mildew pathogen. Proc. R. Soc. Lond. B. 246:83-90.

Brown, J. K. M., O'Dell, M., Simpson, C. G., and Wolfe, M. S. 1990. The use of DNA polymorphisms to test hypotheses about a population of Erysiphe graminis f. sp. hordei. Plant Pathol. 39:391-401.

Brown, J. K. M., Simpson, C. G., and Wolfe, M. S. 1993. Adaptation of barley powdery mildew populations in England to varieties with two resistance genes. Plant Pathol. 42:108-115.

Cannon, R. D., Lamping, E., Holmes, A. R., Niimi, K., Baret, P. V., Keniya, M. V., Tanabe, K., Niimi, M., Goffeau, A., and Monk, B. C. 2009. Efflux-mediated antifungal drug resistance. Clin. Microbiol. Rev. 22:291-321.

Cools, H. J., and Fraaije, B. A. 2013. Update on mechanisms of azole resistance in Mycosphaerella graminicola and implications for future control. Pest Manag. Sci. 69:150-155

Cools, H. J., Mullins, J. G. L., Fraaije, B. A., Parker, J. E., Kelly, D. E., Lucas, J. A., and Kelly, S. L. 2011. Impact of recently emerged sterol $14 \alpha-$ demethylase (CYP51) variants of Mycosphaerella graminicola on azole fungicide sensitivity. Appl. Environ. Microbiol. 77:3830-3837.

Cowger, C., Mehra, L., Arellano, C., Meyers, E., and Murphy, J. P. 2018. Virulence differences in Blumeria graminis f. sp. tritici from the central and eastern United States. Phytopathology 108:402-411.

Cowger, C., Miranda, L., Griffey, C., Hall, M., and Murphy, J. P. 2012. Wheat powdery mildew. Pages 84-119 in: Disease Resistance in Wheat. I. Sharma, ed. Centre for Agricultural Bioscience International, Wallingford, U.K.

Cowger, C., Parks, R., and Kosman, E. 2016. Structure and migration in U.S. Blumeria graminis f. sp. tritici populations. Phytopathology 106:295-304.

Cowger, C., Parks, R., and Marshall, D. 2009. Appearance of powdery mildew of wheat caused by Blumeria graminis f. sp. tritici on Pm17-bearing cultivars in North Carolina. Plant Dis. 93:1219.

de Waard, M. A., Kipp, E. M. C., Horn, N. M., and van Nistelrooy, J. G. M. 1986. Variation in sensitivity to fungicides which inhibit ergosterol biosynthesis in wheat powdery mildew. Neth. J. Plant Pathol. 92:21-32.

Fernandez-Cornejo, J., Nehring, R., Osteen, C., Wechsler, S., Martin, A., and Vialou, A. 2014. Pesticide use in U.S. agriculture: 21 selected crops, 19602008. United States Department of Agriculture, Economic Research Service: EIB-124. https://www.ers.usda.gov/webdocs/publications/43854/46734_eib124.pdf.

Fletcher, J. T., Cooper, S. T., and Prestidge, A. L. H. 1987. An investigation of the sensitivity of Erysiphe graminis f. sp. tritici to various ergosterol inhibiting fungicides. Pages 129-135 in: Integrated Control of Cereal Mildews:
Monitoring the Pathogen. M. S. Wolfe and E. Limpert, eds. Martinus Nijhoff Publishers, Dordrecht, the Netherlands.

Food and Agriculture Organization of the United Nations (FAO). 1998. Pesticide residues in food, 1997 evaluations: FAO Plant Production and Protection Paper 145. FAO Panel of Experts on Pesticide Residues in Food and the Environment, WHO Expert Group on Pesticide Residues, eds. World Health Organization, Geneva, Switzerland.

Food and Agriculture Organization of the United Nations (FAO). 2009. Pesticide residues in food, 2008 toxicological evaluations: FAO Plant Production and Protection Paper 193. FAO Panel of Experts on Pesticide Residues in Food and the Environment, WHO Core Assessment Group on Pesticide Residues, eds. FAO, Rome, Italy.

Fungicide Resistance Action Committee (FRAC). 2013. FRAC Pathogen Risk List 2014. https://edisciplinas.usp.br/pluginfile.php/4893892/mod_folder/content/ 0/pathogen-risk-list.pdf. Accessed November 1, 2019.

Garcia-Effron, G., Dilger, A., Alcazar-Fuoli, L., Park, S., Mellado, E., and Perlin, D. S. 2008. Rapid detection of triazole antifungal resistance in Aspergillus fumigatus. J. Clin. Microbiol. 46:1200-1206.

Gisi, U., Chin, K. M., Knapova, G., Kung Farber, R., Mohr, U., Parisi, S., Sierotzki, H., and Steinfeld, U. 2000. Recent developments in elucidating modes of resistance to phenylamide, DMI and strobilurin fungicides. Crop Prot. 19:863-872.

Godet, F., and Limpert, E. 1998. Recent evolution of multiple resistance of Blumeria (Erysiphe) graminis f. sp. tritici to selected DMI and morpholine fungicides in France. Pest Manag. Sci. 54:244-252.

Hamamoto, H., Hasegawa, K., Nakaune, R., Lee, Y. J., Makizumi, Y., Akutsu, K., and Hibi, T. 2000. Tandem repeat of a transcriptional enhancer upstream of the sterol 14 $\alpha$-demethylase gene (CYP51) in Penicillium digitatum. Appl. Environ. Microbiol. 66:3421-3426.

Hoffmann, G. M. 1986. Control of cereal diseases with modern fungicides in Western Europe. Pages 117-125 in: Fungicide Chemistry: Advances and Practical Applications. M. B. Green and D. A. Spilker, eds. ACS Symposium Series. American Chemical Society, Washington, DC.

Jørgensen, J. H., and Wolfe, M. 1994. Genetics of powdery mildew resistance in barley. Crit. Rev. Plant Sci. 13:97-119.

Kiernan, K., Tao, J., and Gibbs, P. 2012. Tips and strategies for mixed modeling with SAS/STAT ${ }^{\circledR}$ procedures. SAS Global Forum 2012 Paper 332-2012. SAS Institute, Cary, NC. http://support.sas.com/resources/papers/proceedings12/ 332-2012.pdf.

Leroux, P., and Walker, A. S. 2011. Multiple mechanisms account for resistance to sterol $14 \alpha$-demethylation inhibitors in field isolates of Mycosphaerella graminicola. Pest Manag. Sci. 67:44-59.

Lopez, J. A., Rojas, K., and Swart, J. 2015. The economics of foliar fungicide applications in winter wheat in northeast Texas. Crop Prot. 67:35-42.

Ma, Z., Proffer, T. J., Jacobs, J. L., and Sundin, G. W. 2006. Overexpression of the $14 \alpha$-demethylase target gene (CYP51) mediates fungicide resistance in Blumeriella jaapii. Appl. Environ. Microbiol. 72:2581-2585.

McDonald, B. A., and Linde, C. 2002. Pathogen population genetics, evolutionary potential, and durable resistance. Annu. Rev. Phytopathol. 40:349-379.

McIntosh, R. A., Yamazaki, Y., Dubcovsky, J., Rogers, J., Morris, C., Appels, R., and Xia, X. C. 2013. Catalogue of gene symbols for wheat 2013. https:// maswheat.ucdavis.edu/CGSW/GeneSymbol.pdf.

Mikaberidze, A., and McDonald, B. A. 2015. Fitness cost of resistance: Impact on management. Pages 77-89 in: Fungicide Resistance in Plant Pathogens. H. Ishil and D. W. Hollomon, eds. Springer, Tokyo, Japan.

Niewoehner, A. S., and Leath, S. 1998. Virulence of Blumeria graminis f. sp. tritici on winter wheat in the Eastern United States. Plant Dis. 82:64-68.

Noel, Z. A., Wang, J., and Chilvers, M. I. 2018. Significant influence of $\mathrm{EC}_{50}$ estimation by model choice and $\mathrm{EC}_{50}$ type. Plant Dis. 102:708-714.

Parker, J. E., Warrilow, A. G. S., Cools, H. J., Fraaije, B. A., Lucas, J. A., Rigdova K., Griffiths, W. J., Kelly, D. E., and Kelly, S. L. 2013. Prothioconazole and prothioconazole-desthio activities against Candida albicans sterol 14 $\alpha$-demethylase. Appl. Environ. Microbiol. 79:1639-1645.

Parks, R., Carbone, I., Murphy, J. P., and Cowger, C. 2008. Virulence structure of the Eastern U.S. wheat powdery mildew population. Plant Dis. 92:1074-1082.

Price, C. L., Warrilow, A. G. S., Parker, J. E., Mullins, J. G., Nes, W. D., Kelly, D. E., and Kelly, S. L. 2015. Novel substrate specificity and temperature-sensitive activity of Mycosphaerella graminicola CYP51 supported by the native NADPH cytochrome P450 reductase. Appl. Environ. Microbiol. 81:3379-3386.

Rallos, L. E. E., and Baudoin, A. B. 2016. Co-occurrence of two allelic variants of CYP51 in Erysiphe necator and their correlation with over-expression for DMI resistance. PLoS One 11:e0148025.

Schnabel, G., and Jones, A. L. 2001. The 14 $\alpha$-demethylase (CYP51A1) gene is overexpressed in Venturia inaequalis strains resistant to myclobutanil. Phytopathology 91:102-110.

Siegel, M. R. 1981. Sterol-inhibiting fungicides: Effects on sterol biosynthesis and sites of action. Plant Dis. 65:986-989.

Švec, M., Miklovicova, M., Sykora, M., and Krippel, E. 1995. Fungicide sensitivity of populations of wheat powdery mildew (Erysiphe graminis $\mathrm{f} . \mathrm{sp}$ tritici) in central Europe in 1993. Pestic. Sci. 43:47-52.

Thelin, G. P. and Stone, W. W. 2013. Estimation of annual agricultural pesticide use for counties of the conterminous United States, 1992-2009. Scientific Investigation Report 2013-5009. U.S. Geological Survey, Washington, DC. 
Thompson, N. M., Epplin, F. M., Edwards, J. T., and Hunger, R. M. 2014. Economics of foliar fungicides for hard red winter wheat in the USA southern Great Plains. Crop Prot. 59:1-6.

Tucker, M. A., Lopez-Ruiz, F., Jayasena, K., and Oliver, R. P. 2015. Origin of fungicide-resistant barley powdery mildew in Western Australia: Lessons to be learned. Pages 329-340 in: Fungicide Resistance in Plant Pathogens. H. Ishii and D. W. Hollomon, eds. Springer, Tokyo, Japan.

van den Bosch, F., Oliver, R., van den Berg, F., and Paveley, N. 2014. Governing principles can guide fungicide-resistance management tactics. Annu. Rev. Phytopathol. 52:175-195.

Villani, S. M., Hulvey, J., Hily, J. M., and Cox, K. 2016. Overexpression of the CYP51A1 gene and repeated elements are associated with differential sensitivity to DMI fungicides in Venturia inaequalis. Phytopathology 106: 562-571.

Wicker, T., Oberhaensli, S., Parlange, F., Buchmann, J. P., Shantalina, M., Roffler, S., Ben-David, R., Dolezel, J., Simkova, H., Schulze-Lefert, P., Spanu, P. D., Bruggmann, R., Amselem, J., Quesneville, H., Ver Loren van Themaat, E.,
Paape, T., Shimizu, K. K., and Keller, B. 2013. The wheat powdery mildew genome shows the unique evolution of an obligate biotroph. Nat. Genet. 45: 1092-1096.

Wiersma, A. T., Pulman, J. A., Brown, L. K., Cowger, C., and Olson, E. L. 2017. Identification of Pm58 from Aegilops tauschii. Theor. Appl. Genet. 130: 1123-1133.

Wolfe, M. S., and Limpert, E., eds. 1987. Integrated Control of Cereal Mildews: Monitoring the Pathogen. Proceedings of a Seminar in the Community Programme of Coordinated Research on Energy in Agriculture. Martinus Nijhoff Publishers, Dordrecht, the Netherlands.

Wyand, R. A., and Brown, J. K. M. 2005. Sequence variation in the CYP51 gene of Blumeria graminis associated with resistance to sterol demethylase inhibiting fungicides. Fungal Genet. Biol. 42:726-735.

Zulak, K. G., Cox, B. A., Tucker, M. A., Oliver, R. P., and Lopez-Ruiz, F. J. 2018 Improved detection and monitoring of fungicide resistance in Blumeria graminis f. sp. hordei with high-throughput genotype quantification by digital PCR. Front. Microbiol. 9:706. 